\title{
Persistent Systemic Inflammation Is Associated With Bleeding Risk in Atrial Fibrillation Patients
}

\author{
Yuma Hamanaka, MD; Yohei Sotomi, MD, PhD; Akio Hirata, MD, PhD; \\ Tomoaki Kobayashi, MD; Yasuhiro Ichibori, MD, PhD; Nobuhiko Makino, MD, PhD; \\ Takaharu Hayashi, MD, PhD; Yasushi Sakata, MD, PhD; \\ Atsushi Hirayama, MD, PhD; Yoshiharu Higuchi, MD, PhD
}

\begin{abstract}
Background: This study investigated the impact of systemic inflammation on bleeding risk in non-valvular atrial fibrillation (NVAF) patients treated with direct oral anticoagulants (DOAC).

Methods and Results: We conducted a single-center prospective registry of 2,216 NVAF patients treated with DOAC: the DIRECT registry (UMIN000033283). High-sensitivity C-reactive protein (hSCRP) was measured $\leq 3$ months before (pre-DOAC hsCRP) and $6 \pm 3$ months after initiation of DOAC (post-DOAC hsCRP). Multivariate logistic regression model was used to assess the influence of systemic inflammation and conventional bleeding risk factors on major bleeding according to International Society on Thrombosis and Haemostasis criteria. Based on the findings, we created a new bleeding risk assessment score: the ORBIT-i score, which included post-DOAC hsCRP $>0.100 \mathrm{mg} / \mathrm{dL}$ and all components of the ORBIT score. A total of 1,848 patients had both pre- and post-DOAC hsCRP data (follow-up duration, 460 \pm 388 days). Post-DOAC hsCRP was associated with major bleeding (OR, 2.770; $95 \% \mathrm{Cl}: 1.687-4.548, \mathrm{P}<0.001)$. Patients with post-DOAC hsCRP $>0.100 \mathrm{mg} / \mathrm{dL}$ more frequently had major bleeding than those without (log-rank test, $\mathrm{P}<0.001)$. ORBIT-i score had the highest $\mathrm{C}$-index of $0.711(95 \% \mathrm{Cl}, 0.654-0.769)$ compared with the ORBIT and HAS-BLED scores.
\end{abstract}

Conclusions: Persistent systemic inflammation was associated with major bleeding risk. ORBIT-i score had a higher discriminative performance compared with the conventional bleeding risk scores.

Key Words: Atrial fibrillation; Direct oral anticoagulant; High-sensitivity C-reactive protein; ORBIT-i score

I $\mathrm{n}$ daily clinical practice, bleeding risk assessment in patients with atrial fibrillation (AF) is of paramount importance, given that bleeding events in patients with cardiovascular disease can be life-threatening. ${ }^{1-5}$ In order to assess the bleeding risk precisely and objectively, we can use the bleeding risk assessment scores, ORBIT or HAS-BLED scores. ${ }^{2,46}$ The previously reported bleeding risk factors are older age, anemia, bleeding history, insufficient kidney function, treatment with antiplatelets, hypertension, stroke, labile international normalized ratio and so on. ${ }^{2,4}$ No factors associated with systemic inflammation have been reported to date. Several studies, however, suggested that systemic inflammation could play a critical role in the subsequent cardiovascular events, ${ }^{7-9}$ therefore it is highly possible that activation of systemic inflammatory status could predict subsequent bleeding events.

The purpose of the present study was to investigate the impact of systemic inflammation on subsequent bleeding

\section{Editorial p 376}

risk in non-valvular AF (NVAF) patients treated with direct oral anticoagulants (DOAC).

Methods
Subjects
We conducted a single-center prospective observational
registry of NVAF patients with DOAC: Safety and effec-
tiveness of 4 Different dIrect oRal anticoagulants, dabiga-
tran, rivaroxaban, apixaban and edoxaban in rEal-world
Clinical pracTice (DIRECT registry; UMIN000033283).
All serial adult patients (aged $\geq 18$ years) at Osaka Police
Hospital with NVAF who were users of dabigatran, rivar-
oxaban, apixaban, or edoxaban from June 2011 to November
2017 were enrolled. If a patient ever used DOAC during

Received November 11, 2019; revised manuscript received December 27, 2019; accepted January 7, 2020; J-STAGE Advance Publication released online February 11, 2020 Time for primary review: 16 days

Department of Cardiology, Osaka Police Hospital, Osaka (Y. Hamanaka, Y. Sotomi, A. Hirata, T.K., Y.I., N.M., T.H., A. Hirayama, Y. Higuchi); Department of Cardiovascular Medicine, Osaka University Graduate School of Medicine, Suita (Y. Sakata), Japan

Mailing address: Yohei Sotomi, MD, PhD, FACC, FESC, Department of Cardiology, Osaka Police Hospital, 10-31 Kitayama, Tennoji-ku, Osaka 543-0035, Japan. E-mail: sotomiyohei@gmail.com

ISSN-1346-9843 All rights are reserved to the Japanese Circulation Society. For permissions, please e-mail: cj@j-circ.or.jp 


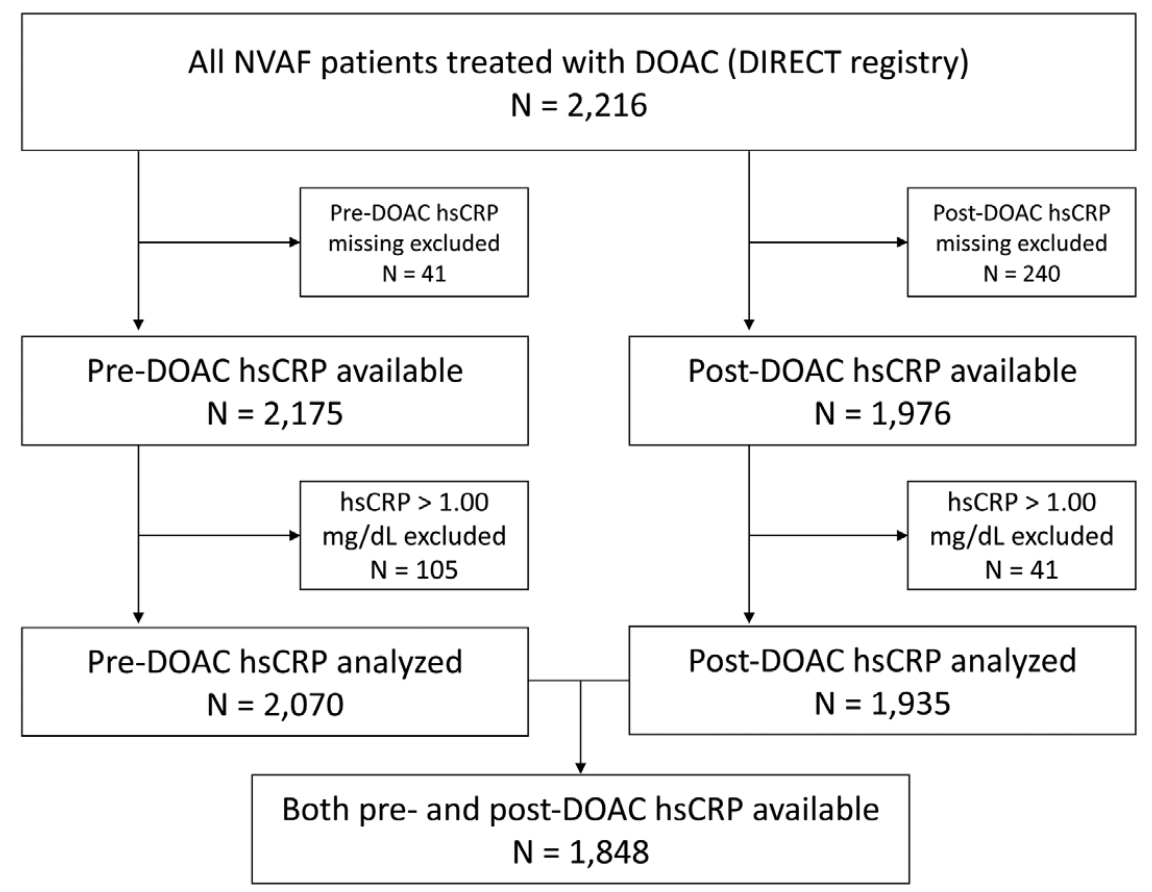

Figure 1. Patient selection and study flowchart. DOAC, direct oral anticoagulant; hsCRP, high-sensitivity C-reactive protein; NVAF, non-valvular atrial fibrillation.

the study period, the first intake of DOAC was defined as the index medication. The treatment period was defined as the time from the first use of a drug to last follow-up or 2 days after the trial drugs were discontinued if the patient stopped the medication. Written informed consent was obtained from all enrolled patients. This study was approved by the Osaka Police Hospital Ethics Committee.

\section{High-Sensitivity C-Reactive Protein (hsCRP)}

In the present cohort, almost all patients undergo routine blood sampling. hsCRP as an inflammatory marker is routinely measured. The present post-hoc study of the DIRECT registry assessed a possible anti-inflammatory effect of DOAC. Baseline inflammatory status was assessed using hsCRP $\leq 3$ months before the start of DOAC (preDOAC hsCRP). Post-DOAC inflammatory status was assessed on hsCRP $6 \pm 3$ months after the start of DOAC (post-DOAC hsCRP). If a patient had major bleeding $\leq 6 \pm 3$ months after the initiation of DOAC, hsCRP measurement in a stable condition during DOAC treatment was selected as the post-DOAC hsCRP. Patients with hsCRP $>1.00 \mathrm{mg} / \mathrm{dL}$ at either time were excluded from analysis due to the possibility of other systemic inflammatory conditions. Patients with no hsCRP data at either time were also excluded. Delta-hsCRP was defined as the difference in hsCRP from before to after treatment.

\section{Endpoints}

The clinical endpoint of interest in the current study was major bleeding, which was defined, according to the International Society on Thrombosis and Haemostasis criteria, as clinically overt bleeding accompanied by a decrease in hemoglobin $\geq 2 \mathrm{~g} / \mathrm{dL}$ or transfusion $\geq 2$ units packed red cells, occurring at a critical site, or resulting in death. ${ }^{10}$ Clinical impact of the systemic inflammatory status, represented as hsCRP, in addition to the known bleeding factors (components of the ORBIT bleeding score ${ }^{4}$ ) on major bleeding risk were assessed in the present study. Clinical events were monitored by questioning, physical examination, laboratory test, and electrocardiogram at each outpatient visit every 2-4 months. The independent clinical event committee, whose members were unaware of the treatment group, adjudicated all clinical events.

\section{Statistical Analysis}

Categorical variables are expressed as n (\%) and were compared using the chi-squared test or Fisher exact test. Continuous variables are expressed as mean \pm SD or median (IQR) and were compared using Student's t-test, MannWhitney U-test, ANOVA, or Kruskal-Wallis test as appropriate. Normality of distribution was tested with the Kolmogorov-Smirnov test. Impact of comorbidities on major bleeding was assessed on multivariate binary logistic regression modeling and Cox proportional hazard modeling as appropriate. As noted, candidate variables for the model were chosen from the individual components of the ORBIT score in addition to the pre- and post-DOAC hsCRP. ${ }^{4}$

In the present study, post-DOAC hsCRP was clinically relevant to major bleeding. Major bleeding was assessed according to systemic inflammatory status (hsCRP $>0.100 \mathrm{mg} / \mathrm{dL}$ vs. $\leq 0.100 \mathrm{mg} / \mathrm{dL}$ ) in a time-to-first-event fashion on Kaplan-Meier analysis and compared using the log-rank test. The best cut-off for discriminating patients with and without major bleeding events was assessed using receiver operating characteristic (ROC) curves. The more 
Table 1. Patient Characteristics vs. Post-DOAC hsCRP

\begin{tabular}{|c|c|c|c|}
\hline \multirow{2}{*}{ Variable } & \multicolumn{2}{|c|}{ Post-DOAC hsCRP } & \multirow{2}{*}{ P-value } \\
\hline & $>0.100 \mathrm{mg} / \mathrm{dL}(\mathrm{n}=579)$ & $\leq 0.100 \mathrm{mg} / \mathrm{dL}(\mathrm{n}=1,269)$ & \\
\hline Age (years) & $72.75 \pm 10.13,74.00(66.00-80.00)$ & $70.14 \pm 10.78,72.00(65.00-78.00)$ & $<0.001$ \\
\hline Female & $210(36.3)$ & $464(36.6)$ & 0.917 \\
\hline Body weight $(\mathrm{kg})$ & $63.28 \pm 15.52,62.90(52.05-72.00)$ & $60.90 \pm 13.41,60.70(51.20-69.80)$ & 0.001 \\
\hline BMI $\left(\mathrm{kg} / \mathrm{m}^{2}\right)$ & $24.28 \pm 4.60,23.96(21.55-26.67)$ & $23.25 \pm 3.67,23.11(20.97-25.31)$ & $<0.001$ \\
\hline Persistent or long-standing persistent AF & $230(39.9)$ & 479 (37.9) & 0.439 \\
\hline Hypertension ${ }^{\dagger}$ & $445(76.9)$ & $920(72.5)$ & 0.052 \\
\hline Diabetes mellitus & $176(30.4)$ & $349(27.5)$ & 0.201 \\
\hline Dyslipidemia $\ddagger$ & $416(71.8)$ & $824(65.0)$ & 0.004 \\
\hline Statin use & $208(35.9)$ & $462(36.4)$ & 0.876 \\
\hline Hemoglobin (g/dL) & $13.37 \pm 2.04,13.40(12.00-14.80)$ & $13.43 \pm 1.89,13.40(12.20-14.80)$ & 0.513 \\
\hline Coronary artery disease & $111(19.2)$ & $267(21.0)$ & 0.384 \\
\hline History of $\mathrm{PCl}$ or $\mathrm{CABG}$ & $64(11.1)$ & $144(11.3)$ & 0.937 \\
\hline PVD & $46(9.1)$ & $75(7.1)$ & 0.188 \\
\hline History of heart failure & $150(25.9)$ & $256(20.2)$ & 0.006 \\
\hline History of stroke & $111(19.2)$ & $193(15.2)$ & 0.036 \\
\hline History of bleeding & $160(27.6)$ & $338(26.6)$ & 0.652 \\
\hline $\mathrm{CHADS}_{2}$ score & $2.17 \pm 1.36,2.00(1.00-3.00)$ & $1.86 \pm 1.34,2.00(1.00-3.00)$ & $<0.001$ \\
\hline DOAC & & & 0.284 \\
\hline Dabigatran & $160(27.6)$ & $402(31.7)$ & \\
\hline Rivaroxaban & $142(24.5)$ & $314(24.7)$ & \\
\hline Apixaban & $163(28.2)$ & $327(25.8)$ & \\
\hline Edoxaban & $114(19.7)$ & $226(17.8)$ & \\
\hline Antiplatelet therapy & $119(20.6)$ & $273(21.5)$ & 0.668 \\
\hline No. antiplatelet agents & & & 0.620 \\
\hline None & $460(79.4)$ & $996(78.5)$ & \\
\hline Single antiplatelet agent & $105(18.1)$ & $231(18.2)$ & \\
\hline Dual antiplatelet agents & $14(2.4)$ & $42(3.3)$ & \\
\hline \multicolumn{4}{|l|}{ Antiplatelet agent } \\
\hline Aspirin & $82(14.2)$ & $214(16.9)$ & 0.151 \\
\hline Clopidogrel & $38(6.6)$ & $72(5.7)$ & 0.459 \\
\hline Prasugrel & $0(0.0)$ & $5(0.4)$ & 0.333 \\
\hline Cilostazol & $10(1.7)$ & $21(1.7)$ & $>0.999$ \\
\hline Ticlopidine & $3(0.5)$ & $3(0.2)$ & 0.385 \\
\hline Insufficient kidney function & $264(45.6)$ & $467(36.8)$ & $<0.001$ \\
\hline Creatinine (mg/dL) & $0.92 \pm 0.30,0.87(0.72-1.04)$ & $0.85 \pm 0.26,0.82(0.68-0.98)$ & $<0.001$ \\
\hline Creatinine clearance ( $\mathrm{mL} / \mathrm{min})$ & $67.97 \pm 31.88,62.21(46.65-82.67)$ & $71.18 \pm 28.80,68.21(50.82-85.92)$ & 0.031 \\
\hline eGFR $\left(\mathrm{mL} / \mathrm{min} / 1.73 \mathrm{~m}^{2}\right)$ & $62.39 \pm 18.98,61.50(50.20-73.85)$ & $66.44 \pm 18.89,66.00(54.50-77.50)$ & $<0.001$ \\
\hline Liver dysfunction & $227(39.2)$ & $377(29.7)$ & $<0.001$ \\
\hline HAS-BLED score $§$ & $2.64 \pm 1.24,3.00(2.00-3.00)$ & $2.42 \pm 1.29,2.00(2.00-3.00)$ & $<0.001$ \\
\hline ORBIT score§ & $2.38 \pm 1.87,2.00(1.00-4.00)$ & $2.11 \pm 1.84,2.00(0.00-3.00)$ & 0.004 \\
\hline ORBIT-i score & $5.38 \pm 1.87,5.00(4.00-7.00)$ & $2.11 \pm 1.84,2.00(0.00-3.00)$ & $<0.001$ \\
\hline Follow-up duration (days) & $\begin{array}{c}405.61 \pm 356.95 \\
350.00(112.00-605.50)\end{array}$ & $\begin{array}{c}484.10 \pm 399.35 \\
399.00(167.62-704.00)\end{array}$ & $<0.001$ \\
\hline
\end{tabular}

Data given as mean $\pm S D$, median (IQR) or as $n(\%)$. †Blood pressure $\geq 140 / 90 \mathrm{mmHg}$ or the use of antihypertensive drug. $\neq$ Treatment with medication or serum low-density lipoprotein cholesterol $\geq 140 \mathrm{mg} / \mathrm{dL}$. \$Missing data handled with multiple imputation, details of which are described elsewhere. ${ }^{3} \mathrm{AF}$, atrial fibrillation; BMI, body mass index; CABG, coronary artery bypass graft; DOAC, direct oral anticoagulant; eGFR, estimated glomerular filtration rate; hsCRP, high-sensitivity C-reactive protein; PCI, percutaneous coronary intervention; PVD, peripheral vascular disease.

practical value of $0.100 \mathrm{mg} / \mathrm{dL}$ was decided based on the best post-DOAC hsCRP cut-off of $0.095 \mathrm{mg} / \mathrm{dL}$. We created the new, modified ORBIT score, which included a factor related to inflammation (post-DOAC hsCRP). Missing data for the ORBIT score were handled with multiple imputation. Details of the multiple imputation are described elsewhere. ${ }^{3}$ Point values were assigned to each ORBIT predictor according to its strength of association with major bleeding. Points for the original ORBIT components were the same as for the original scoring system. ${ }^{4}$ Based on the OR of hsCRP obtained on binary logistic regression analysis in the current cohort (follow-up duration, 460 \pm 388 days), 3 points were assigned to hsCRP (minute elevation of hsCRP; CRP $>0.100 \mathrm{mg} / \mathrm{dL}$ ). Adding this hsCRP 
Table 2. ORBIT Components, Systemic Inflammation (hsCRP) and Major Bleeding (Binary Logistic Regression Model)

\begin{tabular}{|c|c|c|c|c|c|}
\hline \multirow{2}{*}{ Variables } & \multicolumn{2}{|c|}{ Univariate analysis } & \multicolumn{2}{|c|}{ Multivariate analysis } & \multirow{2}{*}{$\begin{array}{l}\text { ORBIT-i } \\
\text { (points) }\end{array}$} \\
\hline & OR $(95 \% \mathrm{Cl})$ & P Value & OR (95\% Cl) & P-value & \\
\hline Older age ( $\geq 75$ years) & $1.539(0.948-2.499)$ & 0.081 & $1.053(0.627-1.766)$ & 0.846 & 1 \\
\hline Reduced hemoglobin/Hct/anemia & $2.134(1.313-3.468)$ & 0.002 & $1.763(1.062-2.926)$ & 0.028 & 2 \\
\hline Bleeding history & $2.356(1.445-3.84)$ & 0.001 & $2.094(1.259-3.484)$ & 0.004 & 2 \\
\hline Insufficient kidney function & $1.652(1.017-2.683)$ & 0.043 & $1.328(0.797-2.214)$ & 0.277 & 1 \\
\hline Treatment with antiplatelets & $1.149(0.649-2.035)$ & 0.634 & $0.936(0.519-1.689)$ & 0.827 & 1 \\
\hline $\begin{array}{l}\text { inflammation (post-DOAC hsCRP } \\
>0.100 \mathrm{mg} / \mathrm{dL} \text { ) }\end{array}$ & $2.901(1.779-4.732)$ & $<0.001$ & $2.770(1.687-4.548)$ & $<0.001$ & 3 \\
\hline $\begin{array}{l}\text { inflammation (pre-DOAC hsCRP } \\
>0.100 \mathrm{mg} / \mathrm{dL} \text { ) }\end{array}$ & $1.670(1.027-2.716)$ & 0.039 & $\begin{array}{l}\text { Not included } \\
\text { in the model }\end{array}$ & & \\
\hline $\begin{array}{l}\text { delta hsCRP (from before to after) } \\
(\mathrm{mL} / \mathrm{dL})\end{array}$ & $7.830(1.258-48.718)$ & 0.027 & $\begin{array}{l}\text { Not included } \\
\text { in the model }\end{array}$ & & \\
\hline
\end{tabular}

DOAC, direct oral anticoagulant; Hct, hematocrit; hsCRP, high-sensitivity C-reactive protein.

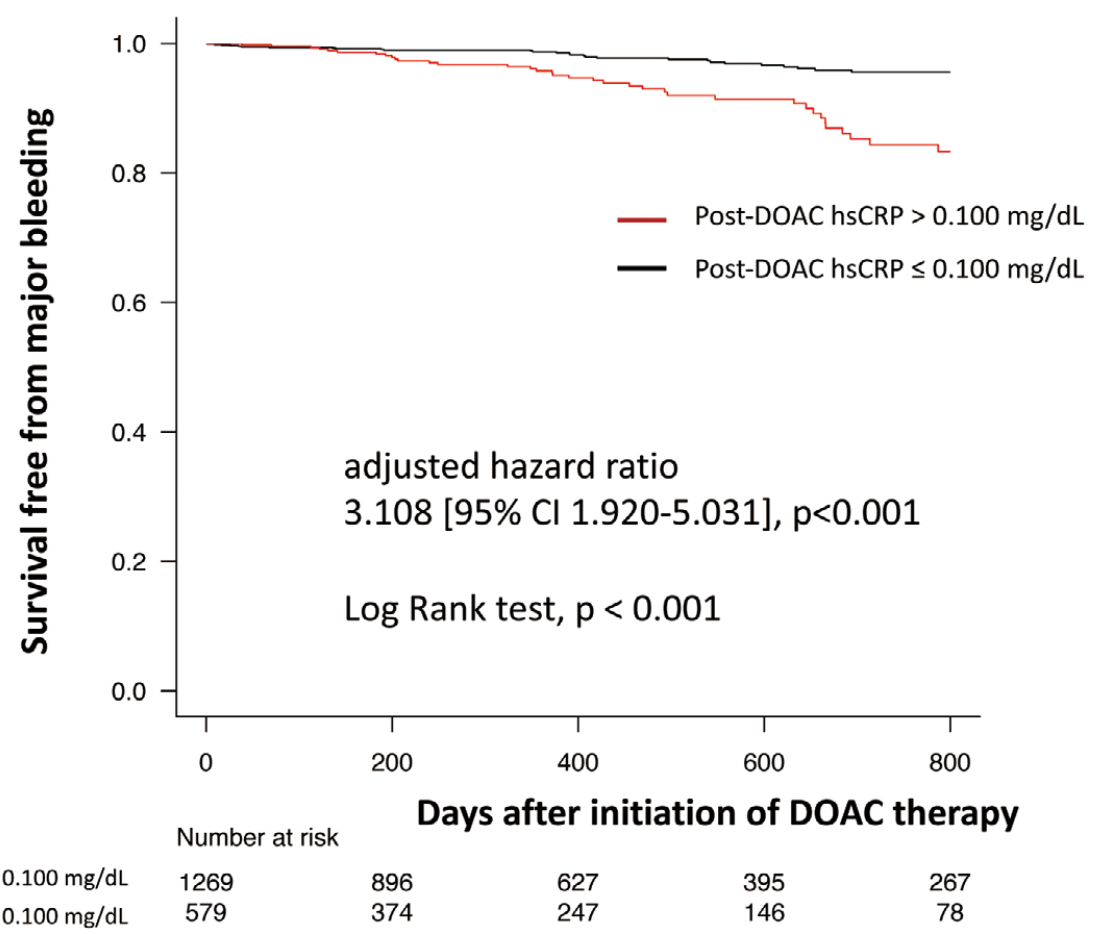

Figure 2. Kaplan-Meier analysis for major bleeding according to post-direct oral anticoagulant therapy (post-DOAC) highsensitivity C-reactive protein (hsCRP) status. Patients with post-DOAC hsCRP $>0.100 \mathrm{mg} / \mathrm{dL}$ more frequently had major bleeding than those with post-DOAC hsCRP $\leq 0.100 \mathrm{mg} / \mathrm{dL}$ (log-rank test; $\mathrm{P}<0.001$ ). Cox regression analysis was performed with multivariate adjustment for older age, reduced hemoglobin, bleeding history, insufficient kidney function, and treatment with antiplatelets.

component (inflammation), we modified the ORBIT score and created new bleeding risk assessment score "ORBIT-i score." ROC curves were used to assess the discrimination ability of the ORBIT score, ORBIT-i score, HAS-BLED score, pre-DOAC hsCRP, post-DOAC hsCRP and deltahsCRP to predict major bleeding in the whole population. ${ }^{\mathbf{1 1}, 12}$ The discriminative performance was studied using the concordance $(\mathrm{C})$ index, which is identical to the area under the ROC curve. The C-index estimates the probability that, of 2 randomly chosen patients, the patient with the more favorable prognostic score will outlive the patient with the less favorable prognostic score, and ranges from 0.5 (no discrimination) to a theoretical maximum of $1 . .^{13,14}$

As an exploratory analysis, we tested the hypothesis that DOAC can suppress systemic inflammation. We compared pre- and post-DOAC hsCRP in a paired manner using the Wilcoxon signed ranks test. $\mathrm{P}<0.05$ was considered statistically significant. All analyses were undertaken using SPSS 24.0 (IBM Corporation, Armonk, NY, USA) or R (version 3.6.2; R Foundation for Statistical Computing, Vienna, Austria). 


\section{Follow-up duration: $460 \pm 388$ days}

\section{$14.0 \%$}

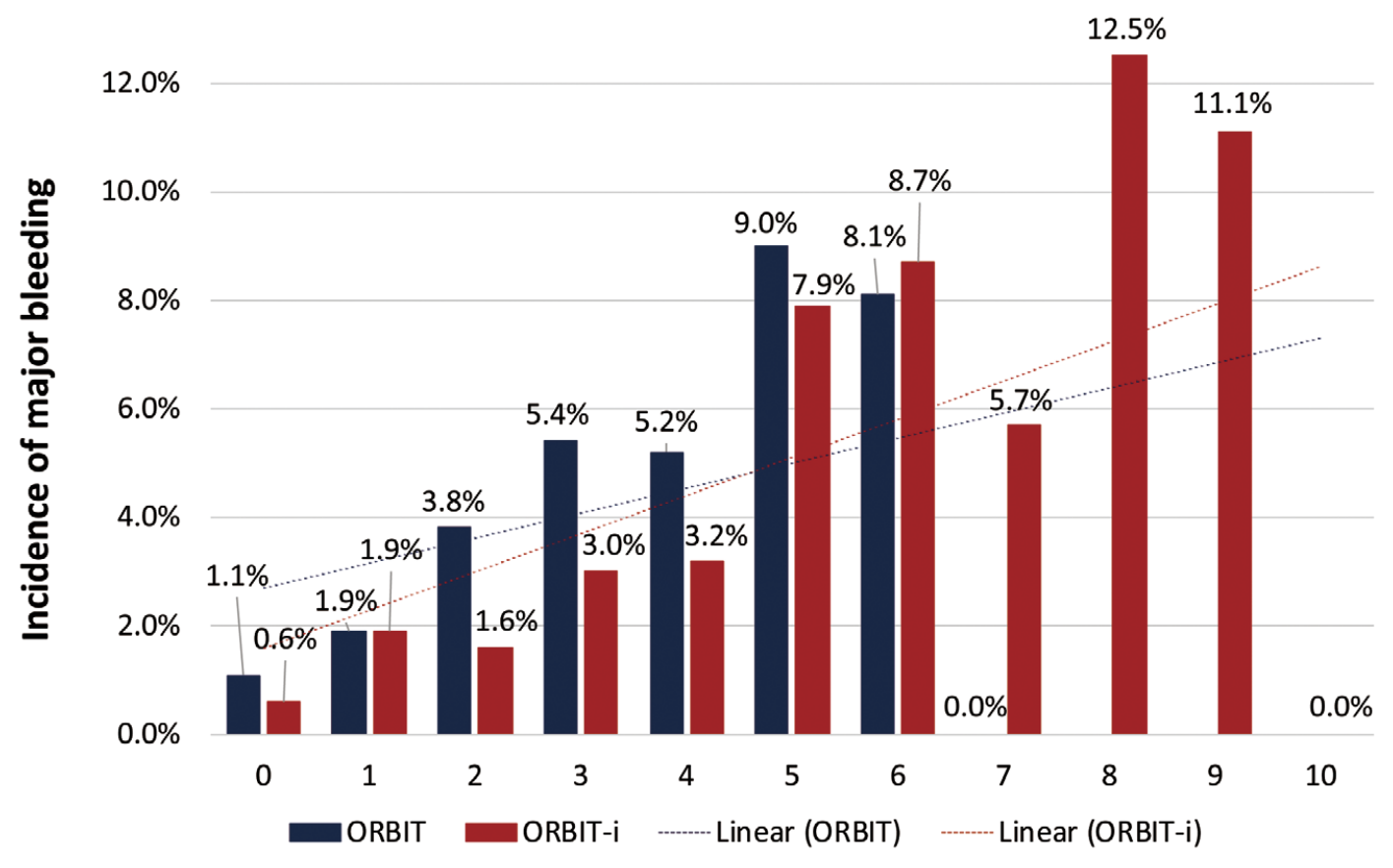

Figure 3. One-year incidence or major bleeding stratified vs. ORBIT and ORBIT-i scores (follow-up duration: $460 \pm 388$ days).

\section{Results}

\section{Subjects}

All patients with NVAF $(n=2,216)$ who were users of dabigatran $(n=648)$, rivaroxaban $(n=538)$, apixaban $(n=599)$, or edoxaban $(n=431)$ from June 2011 to November 2017 were enrolled (mean age, $71.6 \pm 10.8$ years; $36.4 \%$ female; follow-up duration, 407.2 \pm 388.3 days). Pairwise hsCRP (both before and after) was available in a total of 1,848 patients. Patient selection is shown in Figure 1. Characteristics of the patients analyzed $(n=1,848)$ and excluded $(n=368)$ from the analysis are listed in Supplementary Table 1. Baseline characteristics of the study cohort $(n=1,848)$ stratified by post-DOAC hsCRP (hsCRP $>0.100 \mathrm{mg} / \mathrm{dL}$ vs. $\leq 0.100 \mathrm{mg} / \mathrm{dL}$ ) are listed in Table 1. Patients with postDOAC hsCRP $>0.100 \mathrm{mg} / \mathrm{dL}$ were slightly older and more frequently had dyslipidemia and insufficient kidney function than those with post-DOAC hsCRP $\leq 0.100 \mathrm{mg} / \mathrm{dL}$.

\section{Impact of hsCRP on Major Bleeding}

In the current cohort $(n=1,848), 68$ patients $(3.7 \%)$ had major bleeding. In the overall cohort, blood sampling for pre-DOAC hsCRP and post-DOAC hsCRP was performed a median of 1 day (IQR, 0-28.4 days) before and 189 days (IQR, 150-231 days) after the initiation of DOAC therapy, respectively. In patients who had major bleeding, median time from post-DOAC hsCRP to bleeding event was 96 days (IQR, 15-208 days). On univariate analysis with the binary logistic regression model, pre-DOAC hsCRP $(\mathrm{P}=0.039)$, post-DOAC hsCRP $(\mathrm{P}<0.001)$, and delta hsCRP $(\mathrm{P}=0.027)$ were all significantly associated with major bleeding. Of these inflammatory factors, post-DOAC hsCRP was the strongest predictor of major bleeding (OR, 2.901; 95\% CI: 1.779-4.732, $\mathrm{P}<0.001$; Table 2). We included only post-DOAC hsCRP in the multivariate model in addition to the ORBIT components. With regard to the ORBIT components, similar results were obtained to those for the original ORBIT cohort. ${ }^{4}$ Post-DOAC hsCRP $>0.100 \mathrm{mg} / \mathrm{dL}$ was associated with a higher major bleeding risk (OR, 2.770; 95\% CI: 1.687-4.548, P<0.001). Patients with post-DOAC hsCRP $>0.100 \mathrm{mg} / \mathrm{dL}$ more frequently had major bleeding than those with post-DOAC hsCRP $\leq 0.100 \mathrm{mg} / \mathrm{dL}$ (adjusted HR, 3.108; 95\% CI: 1.920-5.031, Cox proportional hazard modeling, $\mathrm{P}<0.001$; log-rank test, $\mathrm{P}<0.001$; Figure 2).

\section{ORBIT and ORBIT-i Scores}

Based on the OR of hsCRP in the current cohort, 3 points were assigned to the minute elevation of inflammatory marker (post-DOAC hsCRP $>0.100 \mathrm{mg} / \mathrm{dL}$ ). Adding this inflammatory component, we created a new bleeding risk assessment score: ORBIT-i score (Table 2). Figure 3 illustrates the incidence of major bleeding stratified by ORBIT and ORBIT-i scores. The ORBIT-i score more clearly stratified bleeding risk than the ORBIT score. Discriminative performance was assessed using C-index. ORBIT-i score had the highest C-index of 0.711 (95\% CI: 0.654 0.769 ) compared with ORBIT, HAS-BLED, pre- and postDOAC hsCRP, and delta-hsCRP (Figure 4). The best ORBIT-i score cut-off was 5.0 (sensitivity, $60.3 \%$; specificity, $73.8 \%$ ). 


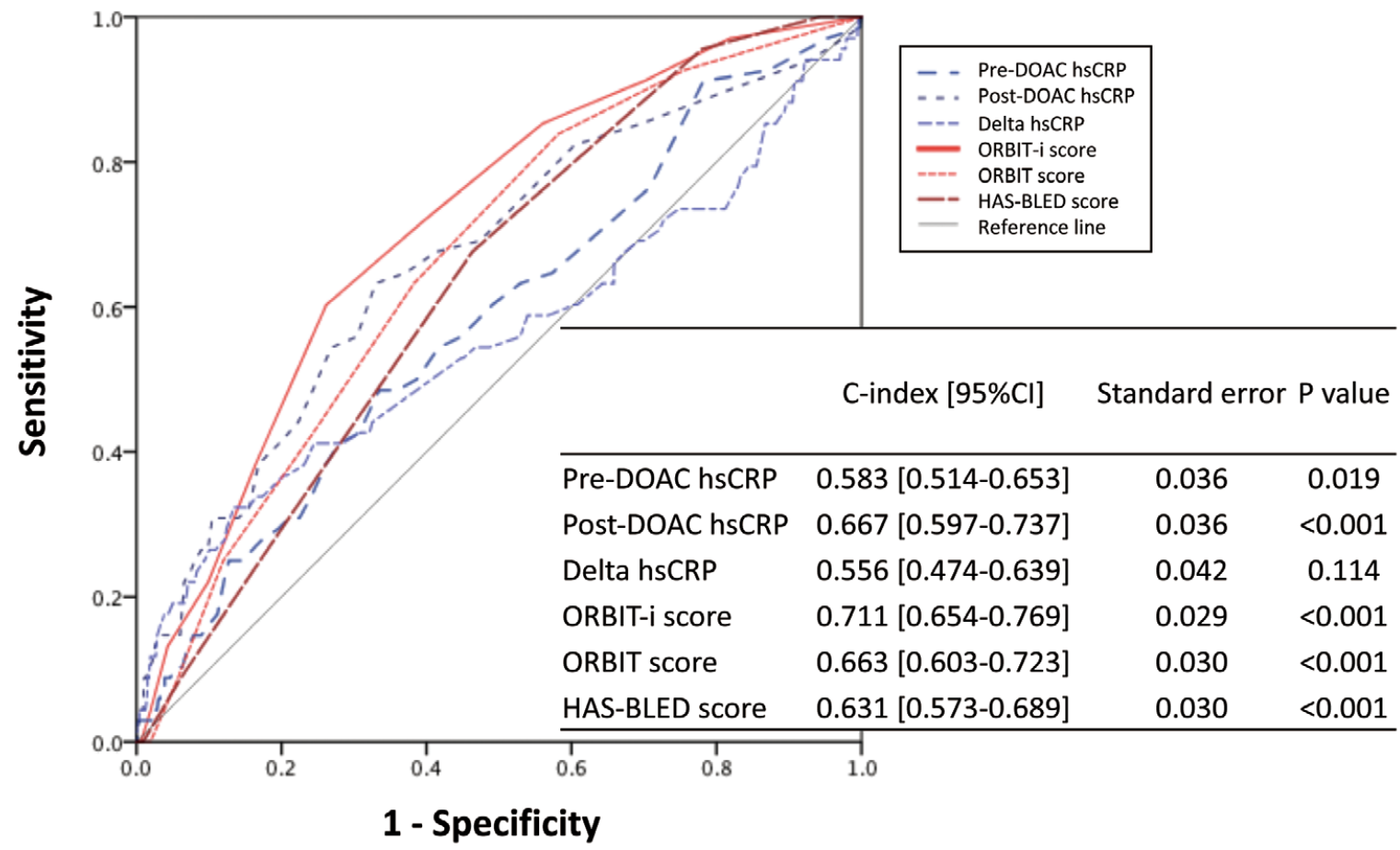

Figure 4. Discriminative performance (C-index) for major bleeding. The best-cut-off of the ORBIT-i score was 5.0 (sensitivity $60.3 \%$; specificity $73.8 \%$ ).

\begin{tabular}{|lccccc|}
\hline \multicolumn{2}{|l}{ Table 3. Change in hsCRP After DOAC Therapy } & & & \\
& $\mathbf{n}$ & $\begin{array}{c}\text { Pre-DOAC } \mathbf{h s C R P}(\mathbf{m g} / \mathbf{d L}) \\
\text { Median (IQR) }\end{array}$ & $\begin{array}{c}\text { Post-DOAC hsCRP (mg/dL) } \\
\text { Median (IQR) }\end{array}$ & $\begin{array}{c}\text { Delta hsCRP (mg/dL) } \\
\text { Mean (95\% Cl) }\end{array}$ & $\begin{array}{c}\text { P-value } \\
\text { Overall cohort }\end{array}$ \\
Dabigatran & 1,848 & $0.08(0.04-0.17)$ & $0.06(0.03-0.13)$ & $0.03(0.02-0.04)$ & $<0.001$ \\
Rivaroxaban & 562 & $0.08(0.04-0.16)$ & $0.06(0.03-0.12)$ & $0.04(0.02-0.05)$ & $<0.001$ \\
Apixaban & 456 & $0.07(0.04-0.16)$ & $0.07(0.03-0.13)$ & $0.02(0.01-0.04)$ & 0.001 \\
Edoxaban & 490 & $0.10(0.04-0.19)$ & $0.06(0.03-0.13)$ & $0.04(0.02-0.05)$ & $<0.001$ \\
\hline
\end{tabular}

DOAC, direct oral anticoagulant; hsCRP, high-sensitivity C-reactive protein.

\section{Influence of DOAC on hsCRP}

Supplementary Table 2 summarizes baseline characteristics stratified by DOAC type. Patients treated with apixaban or edoxaban had a higher bleeding risk than those with dabigatran or rivaroxaban. Table 3 lists the change in hsCRP according to DOAC type. In the overall cohort, median hsCRP significantly decreased after the start of DOAC prescription (before, $0.08 \mathrm{mg} / \mathrm{dL}$; IQR, 0.04$0.17 \mathrm{mg} / \mathrm{dL}$ vs. after, $0.06 \mathrm{mg} / \mathrm{dL}$; IQR, $0.03-0.13 \mathrm{mg} / \mathrm{dL}$, $\mathrm{P}<0.001)$. The significant reduction of hsCRP was consistent across all DOAC $(\mathrm{P}=0.342$, ANOVA). The proportion of patients with hsCRP $>0.100 \mathrm{mg} / \mathrm{dL}$ significantly decreased after the start of DOAC (before, $779,42.2 \%$ vs. after, 579, 31.3\%; $\mathrm{P}<0.001)$.

\section{Discussion}

The main findings of the present study are as follows: (1) post-DOAC hsCRP was significantly associated with the subsequent major bleeding risk; (2) modified ORBIT score (ORBIT-i score) including systemic inflammatory status had a higher discriminative performance than ORBIT and HAS-BLED scores in the current cohort; and (3) in the overall cohort, hsCRP significantly decreased after the start of DOAC therapy. The significant reduction of hsCRP was consistent across all DOAC.

\section{Impact of Systemic Inflammation on Major Bleeding Risk}

The question of how inflammation plays a role in cardiovascular disease remains a topic of ongoing research. Several studies indicated that systemic inflammation would play a critical role in the subsequent cardiovascular events..$^{7,8}$ In a previous study, patients with bleeding events had higher hsCRP than those without. ${ }^{9}$ In the present study, post-DOAC hsCRP $>0.100 \mathrm{mg} / \mathrm{dL}$ had the strongest impact on subsequent bleeding risk (OR, 2.770; 95\% CI: 1.6874.548, $\mathrm{P}<0.001)$ compared with pre-DOAC hsCRP and delta-hsCRP. hsCRP was significantly suppressed by 
DOAC therapy and all patients kept using DOAC in the study period. Therefore, post-DOAC hsCRP would comprehensively represent the inflammatory status of the entire follow-up period. This may explain why post-DOAC hsCRP (systemic inflammatory status at stable phase) was most significantly associated with subsequent bleeding events, no matter how high pre-DOAC hsCRP was or no matter how much DOAC suppressed the hsCRP. Previous animal studies suggested an important role of inflammation in bleeding, ${ }^{15}$ whereas little is known about the association between inflammation and bleeding events in the clinical setting. ${ }^{9}$ The present finding suggests that imperceptible but persistent systemic inflammation is associated with the subsequent bleeding events in the real-world clinical setting.

\section{Clinical Utility of the ORBIT-i Score}

We propose the newly modified ORBIT score: the ORBIT-i score, considering the systemic inflammatory status in addition to the conventional bleeding risk factors, older age, anemia, bleeding history, insufficient kidney function, and treatment with antiplatelets. We utilized ORBIT as the base because this score performs better in the current population than the HAS-BLED score. ${ }^{3}$ The ORBIT-i score had a higher discriminative performance compared with the ORBIT and HAS-BLED scores in the current cohort (Figure 4). The ORBIT-i score more clearly stratified bleeding risk than the ORBIT score in the current cohort (Figure 3). CRP would be easy to measure in daily clinical practice. The cut-off of $0.100 \mathrm{mg} / \mathrm{dL}$ does not necessarily require hsCRP, which would enhance the utility of the newly proposed ORBIT-i score. Of note, the assessment of systemic inflammation must be done in the stable phase. When patients start medication affecting systemic inflammation (statin, DOAC etc.), assessment of hsCRP should be done a few months after the initiation of the drugs, which might be a drawback of this prediction tool.

\section{Anti-Inflammatory Effect of DOAC}

In animal studies, activated coagulation factor X (FXa) was shown to play a key role not only in the coagulation cascade but also in the pathophysiology of chronic inflammation in the vasculature. ${ }^{16} \mathrm{FXa}$ stimulates proteaseactivated receptor 2 (PAR2). ${ }^{17}$ The activation of PAR2 promotes pro-inflammatory activation of macrophages, as determined by inflammatory molecule expression and foam cell formation, which promotes vascular inflammation. ${ }^{18}$ The direct thrombin inhibitor also inhibits the expression of pro-inflammatory markers. ${ }^{19,20}$ Accumulating evidence in these animal studies suggests an anti-inflammatory effect of DOAC.

In the clinical setting, however, the anti-inflammatory effect of DOAC was still controversial.,,21 In the present study median hsCRP was significantly reduced $(0.03 \mathrm{mg} / \mathrm{dL}$; IQR, $0.02-0.04 \mathrm{mg} / \mathrm{dL}, \mathrm{P}<0.001) 6 \pm 3$ months after initiation of DOAC therapy. Treatment was not basically changed between pre- and post-DOAC hsCRP assessments, except for initiation of the DOAC. The significant suppression of systemic inflammation was consistent across direct thrombin inhibitor (dabigatran) and FXa inhibitors (rivaroxaban, apixaban, and edoxaban). Given that the analysis was post-hoc, the results were limited to hypothesis generating.

\section{Study Limitations}

First, given that the present study was a single-center prospective registry, patients included in the DIRECT registry represent a selected cohort of NVAF patients. Some patients with missing CRP measurement or with abnormally high CRP were excluded from the current analysis, which might result in a selection bias (Supplementary Table 1). Second, other inflammatory markers (interleukin-6, tumor necrosis factor- $\alpha$ etc.) were not measured. Third, the clinical significance of the suppressed systemic inflammation by DOAC remained unclear. Given that all participants received DOAC therapy, the current study did not have a control arm, and hence did not allow specific analysis of the impact of DOAC therapy. Last, external validation of the newly developed ORBIT-i score was not performed. This must be done in a future study to assure the generalizability of ORBIT-i score.

\section{Conclusions}

In the Asian clinical settings, minute but persistent systemic inflammation was strongly associated with subsequent major bleeding risk. The newly proposed ORBIT-i score, considering the systemic inflammatory status in addition to the conventional bleeding risk factors, had a higher discriminative performance compared with the ORBIT and HAS-BLED scores in the current cohort. Further large-scale trials must be conducted to evaluate the external validity of the ORBIT-i score.

\section{Acknowledgments}

We thank Ayaka Murakami, Tomoe Yamamoto, Ayako Fukao, and Yoko Inoue for their invaluable support in data collection and management.

\section{Funding}

None.

\section{Conflict of Interest}

Y. Sotomi, A. Hirata, A. Hirayama, and Y. Higuchi received research grants, speaker honoraria, and travel expenses from Bayer, DaiichiSankyo, Amgen Astellas BioPharma, Boehringer Ingelheim, BristoleMyers Squibb, Abbott Vascular Japan, Boston Scientific Japan, TERUMO, Cardinal Health, and Medtronic. Y. Sakata received grants and personal fees from Daiichi-Sankyo, Bayer, Boehringer Ingelheim, and Bristol-Myers Squibb. The other authors declare no conflicts of interest.

\section{IRB Information}

This study was approved by the Osaka Police Hospital Ethical Committee (Reference number 979).

\section{References}

1. Valgimigli M, Costa F, Lokhnygina Y, Clare RM, Wallentin L, Moliterno DJ, et al. Trade-off of myocardial infarction vs. bleeding types on mortality after acute coronary syndrome: Lessons from the Thrombin Receptor Antagonist for Clinical Event Reduction in Acute Coronary Syndrome (TRACER) randomized trial. Eur Heart J 2017; 38: 804-810.

2. Pisters R, Lane DA, Nieuwlaat R, de Vos CB, Crijns HJ, Lip GY. A novel user-friendly score (HAS-BLED) to assess 1-year risk of major bleeding in patients with atrial fibrillation: The Euro Heart Survey. Chest 2010; 138: 1093-1100.

3. Mori N, Sotomi Y, Hirata A, Hirayama A, Sakata Y, Higuchi Y. External validation of the ORBIT bleeding score and the HAS-BLED score in nonvalvular atrial fibrillation patients using direct oral anticoagulants (Asian data from the DIRECT Registry). Am J Cardiol 2019; 124: 1044-1048.

4. O'Brien EC, Simon DN, Thomas LE, Hylek EM, Gersh BJ, Ansell JE, et al. The ORBIT bleeding score: A simple bedside score to assess bleeding risk in atrial fibrillation. Eur Heart $J$ 2015; 36: 3258-3264. 
5. Lip GY, Andreotti F, Fauchier L, Huber K, Hylek E, Knight E, et al. Bleeding risk assessment and management in atrial fibrillation patients: A position document from the European Heart Rhythm Association, endorsed by the European Society of Cardiology Working Group on Thrombosis. Europace 2011; 13: 723-746.

6. Lip GY, Banerjee A, Lagrenade I, Lane DA, Taillandier S, Fauchier L. Assessing the risk of bleeding in patients with atrial fibrillation: The Loire Valley Atrial Fibrillation project. Circ Arrhythm Electrophysiol 2012; 5: 941-948.

7. Sotomi Y, Inoue K, Ito N, Kimura R, Toyoshima Y, Masuda $\mathrm{M}$, et al. Incidence and risk factors for very late recurrence of atrial fibrillation after radiofrequency catheter ablation. Europace 2013; 15: $1581-1586$.

8. Nanchen D, Klingenberg R, Gencer B, Raber L, Carballo D, von Eckardstein A, et al. Inflammation during acute coronary syndromes: Risk of cardiovascular events and bleeding. Int $J$ Cardiol 2019; 287: 13-18.

9. Kikuchi S, Tsukahara K, Sakamaki K, Morita Y, Takamura T, Fukui K, et al. Comparison of anti-inflammatory effects of rivaroxaban vs. dabigatran in patients with non-valvular atrial fibrillation (RIVAL-AF study): Multicenter randomized study. Heart Vessels 2019; 34: 1002-1013.

10. Schulman S, Kearon C, Subcommittee on Control of Anticoagulation of the Scientific Standardization Committee of the International Society on Thrombosis and Haemostasis. Definition of major bleeding in clinical investigations of antihemostatic medicinal products in non-surgical patients. J Thromb Haemost 2005; 3: 692-694.

11. Harrell FE Jr, Califf RM, Pryor DB, Lee KL, Rosati RA. Evaluating the yield of medical tests. JAMA 1982; 247: $2543-$ 2546.

12. Pencina MJ, D'Agostino RB Sr. Evaluating discrimination of risk prediction models: The C statistic. JAMA 2015; 314: $1063-$ 1064.

13. Metz CE. Basic principles of ROC analysis. Semin Nucl Med 1978; 8: $283-298$
14. Obuchowski NA. Receiver operating characteristic curves and their use in radiology. Radiology 2003; 229: $3-8$

15. Goerge T, Ho-Tin-Noe B, Carbo C, Benarafa C, RemoldO'Donnell E, Zhao BQ, et al. Inflammation induces hemorrhage in thrombocytopenia. Blood 2008; 111: 4958-4964.

16. Hara T, Fukuda D, Tanaka K, Higashikuni Y, Hirata Y, Nishimoto S, et al. Rivaroxaban, a novel oral anticoagulant, attenuates atherosclerotic plaque progression and destabilization in ApoE-deficient mice. Atherosclerosis 2015; 242: 639-646.

17. Oe Y, Hayashi S, Fushima T, Sato E, Kisu K, Sato H, et al. Coagulation factor $\mathrm{Xa}$ and protease-activated receptor 2 as novel therapeutic targets for diabetic nephropathy. Arterioscler Thromb Vasc Biol 2016; 36: 1525-1533.

18. Hara T, Phuong PT, Fukuda D, Yamaguchi K, Murata C, Nishimoto S, et al. Protease-activated receptor-2 plays a critical role in vascular inflammation and atherosclerosis in apolipoprotein E-deficient mice. Circulation 2018; 138: 1706-1719.

19. Lee IO, Kratz MT, Schirmer SH, Baumhakel M, Bohm M. The effects of direct thrombin inhibition with dabigatran on plaque formation and endothelial function in apolipoprotein E-deficient mice. J Pharmacol Exp Ther 2012; 343: 253-257.

20. Borissoff JI, Otten JJ, Heeneman S, Leenders P, van Oerle R, Soehnlein O, et al. Genetic and pharmacological modifications of thrombin formation in apolipoprotein E-deficient mice determine atherosclerosis severity and atherothrombosis onset in a neutrophildependent manner. PLoS One 2013; 8: e55784.

21. Katoh H, Nozue T, Michishita I. Anti-inflammatory effect of factor-Xa inhibitors in Japanese patients with atrial fibrillation. Heart Vessels 2017; 32: 1130-1136.

\section{Supplementary Files}

Please find supplementary file(s);

http://dx.doi.org/10.1253/circj.CJ-19-1006 